The Journal of Laryngology \& Otology

http://journals.cambridge.org/JLO

Additional services for The Journal of Laryngology \& Otology:

Email alerts: $\underline{\text { Click here }}$

Subscriptions: $\underline{\text { Click here }}$

Commercial reprints: $\underline{\text { Click here }}$

Terms of use : $\underline{\text { Click here }}$

\title{
Is there objective evidence that septal surgery improves nasal airflow?
}

A Singh, N Patel, G Kenyon and G Donaldson

The Journal of Laryngology \& Otology / Volume 120 / Issue 11 / November 2006, pp 916 - 920

DOI: 10.1017/S0022215106003410, Published online: 12 October 2006

Link to this article: http://journals.cambridge.org/abstract_S0022215106003410

How to cite this article:

A Singh, N Patel, G Kenyon and G Donaldson (2006). Is there objective evidence that septal surgery improves nasal airflow?. The Journal of Laryngology \& Otology, 120, pp 916-920 doi:10.1017/S0022215106003410

Request Permissions : $\underline{\text { Click here }}$ 


\title{
Is there objective evidence that septal surgery improves nasal airflow?
}

\author{
A Singh, N Patel, G Kenyon, G Donaldson*
}

\begin{abstract}
Objective: To identify any prospective, controlled trials providing objective evidence of a reduction in nasal airway resistance following nasal septal surgery, and to undertake a meta-analysis of available data.

Methods: A systematic review with meta-analysis of data was undertaken. A systematic review of the literature using a defined search strategy was conducted to identify papers that used objective methods of airway assessment to evaluate the benefit of septal surgery. Accepted techniques for objective airway assessment included acoustic rhinometry, active anterior rhinomanometry and peak nasal inspiratory airflow. Papers were included based on pre-defined criteria, which included standardization of techniques as outlined in the guidelines of the 1984 committee report on the standardization of rhinomanometry.

Results: We identified 942 articles, of which 13 were prospective studies evaluating the objective benefit of nasal septal surgery. Only three of these studies conformed to the inclusion criteria. A meta-analysis on these papers was performed using the Mantel-Haenszel method, and this demonstrated an overall reduction in nasal airway resistance following septal surgery for nasal obstruction $(p=0.018)$.

Conclusions: The majority of studies evaluating the objective benefit of septal surgery did not conform to the recommendations of the committee report on the standardization of rhinomanometry. Only three prospective controlled trials, with pooled data from 141 cases, were identified for meta-analysis. The conclusions that can be drawn concerning objective improvement in airway function following nasal septal surgery are therefore limited. More long-term studies, adhering to standardized techniques, are needed to provide more convincing data.
\end{abstract}

Key words: Nasal Septum; Surgical Procedures, Operative; Rhinomanometry; Rhinometry, Acoustic; Respiratory Function Tests; Review

\section{Introduction}

Few structures in the human body have been operated upon with such frequency and with such a variety of techniques as the nasal septum. In the past, surgery to this area has been advocated as a cure for conditions ranging from psychosis to emphysema, as well as for more seemingly obvious conditions such as epistaxis. ${ }^{1}$ Septal surgery also often forms part of a routine rhinoplasty. ${ }^{2}$

Perhaps the least controversial indication for such surgery is to correct deformity in patients suffering from nasal obstruction, but it has been suggested that the evidence base for this procedure in such patients is lacking. ${ }^{3}$ In spite of this, it is clear that routine septal surgery for nasal obstruction is generally regarded as being successful, and the number of cases on routine operating lists attests to the widely held belief that such procedures are beneficial. Indeed, papers reporting the outcomes of such surgery have suggested that as many as
75 per cent of patients claim benefit from the procedure. $^{4-7}$

Unfortunately, justifying the case for surgery is made more difficult by the knowledge that the findings on clinical examination do not necessarily correlate with the patient's symptoms. ${ }^{8}$ Moreover, assessment by simple physical examination is inherently subjective, as there are no agreed criteria for deciding by how much a turbinate must be hypertrophied or by how much a septum should be deviated before surgery is indicated. This uncertainty is not improved by the lack of agreement surrounding the methodology that should be used for objective measurement of nasal airway performance. Some authors have advocated active anterior ${ }^{9}$ or posterior rhinomanometry, ${ }^{10}$ and criteria for reporting such measurements have been agreed, ${ }^{11}$ but others have suggested that acoustic rhinometry or peak nasal inspiratory flow may be a more reliable technique for measuring airway performance. ${ }^{12-14}$

From the Department of Otolaryngology-Head \& Neck Surgery, Whipps Cross Hospital, and the *Department of Respiratory Medicine and Statistics, St Bartholomew's and the Royal London NHS Trust, London, UK.

Accepted for publication: 24 March 2006. 
The present study was conceived to determine whether there was objective evidence of an improvement in nasal airflow following septal surgery, by reviewing the available literature and by performing a meta-analysis of pooled data from suitable papers.

\section{Materials and methods}

The literature was searched for papers that objectively assessed the outcome of septal surgery (septoplasty or submucous resection) using either one or a combination of the following techniques: acoustic rhinometry, active anterior rhinomanometry or inspiratory nasal peak flow.

The criteria for including studies in this review were as follows. All prospective controlled studies that fulfilled the criteria outlined below and that were in the English language were included. Papers that assessed either adults or children undergoing septoplasty or submucous resection of the septum for nasal obstruction were considered, with the exclusion of those undergoing adjunctive procedures such as turbinate surgery. We considered only those studies in which active anterior rhinomanometry, acoustic rhinometry or inspiratory nasal flow were employed and in which these techniques were used for objective evaluation of nasal airflow both preand post-operatively. Finally, the method of measurement had to conform to that recommended by the committee report on the standardization of rhinomanometry. ${ }^{11}$

The outcome measure sought was an objective change in nasal airflow, as demonstrated either by an altered inspiratory nasal peak flow, by measured changes in nasal volume or by changes in nasal airflow resistance.

\section{Search strategy}

A systematic search of the available literature was undertaken using the computerized databases of Medline (1984-2005), Embase (1984-2005) and the Cochrane Controlled Trials Register, with the added assistance of the Royal Society of Medicine library search services team. The search was later re-run on Medline (1966-1983) and Embase (1974-1983) to avoid missing any relevant earlier papers.

The specific terms searched for were 'rhinomanometry', 'acoustic rhinometry', 'peak flow', 'nasal airflow', 'nasal peak flow', 'nasal patency', 'nasal obstruction', 'nasal airway resistance', 'septoplasty', 'submucous resection', 'nasal septum' and 'nasal surgery'. We also searched for 'nose - airflow', 'peak - inspiratory - flow' and 'inspiratory - flow'.

References from papers cited were also retrieved where it was perceived that these might be relevant.

Papers were only considered for systematic review if they satisfied the following criteria: (a) the publication was in a peer-reviewed journal; (b) the study included clearly defined patient populations recruited by either a single surgeon or from an institution over a defined study period, with all consecutive patients included; (c) there were clearly defined, objective reporting criteria measuring outcome from septal surgery, as assessed by rhinomanometry, peak nasal inspiratory flow or acoustic rhinometry; (d) the study was prospective and adequately controlled; and (e) the study included surgery to the nasal septum alone (in this respect, it was decided to exclude the study if turbinate surgery was also undertaken or if the procedure was performed as part of a rhinoplasty).

\section{Review methods}

Titles, abstracts and citations were independently reviewed by the two reviewers (AS and NP) to assess potential relevance for full review. From the full text, both reviewers independently assessed studies for inclusion based on the agreed criteria. The third reviewer (GK) resolved any differences in opinion.

Judgement of the methodological quality of eligible papers was based on the recommendations from the committee report on the standardization of rhinomanometry. ${ }^{11}$ From these recommendations, absolute criteria for inclusion, which had to be met, were that: (a) the patient had been examined either by rhinoscopy or nasal endoscopy; (b) measurements had been made with the subjects in an upright position; (c) there had been a rest period prior to testing; (d) the measurements had been repeated and the mean results presented; and (e) the measurements had been made with and without decongestion of the nose.

It was decided at the outset that papers reporting results based on post-operative postal questionnaires would be rejected.

\section{Results}

A total of 942 articles was initially identified, relating to either nasal surgery or the objective assessment of nasal airflow. Only 60 of these included some objective assessment of the nasal airway before and after surgery. A further review of these papers identified only 13 prospective studies of the benefit of septal surgery, which used objective techniques to measure changes in nasal airflow. Of these, only three prospective, controlled trials fulfilled our predefined criteria. A summary of the papers which were considered but then rejected after a final reading is tabulated in Table $\mathrm{I}$. Thus, only three papers were available for potential meta-analysis. $6,24,25$

All of the three studies included in the meta-analysis used active anterior rhinomanometry as an objective measure of nasal airway resistance. In this method, the measured resistance is determined from the value of $\mathrm{v}_{2}$ calculated from the intersection of a circle with a radius of 200 Pascal to the abscissa (pressure) and of $200 \mathrm{~cm}^{3} / \mathrm{s}$ to the ordinate (volume) of a derived pressure/volume curve. ${ }^{26}$ The three papers reported trials containing 141 patients in total. In two, septoplasty alone had been performed; ${ }^{6,24}$ in the remaining trial, patients had undergone submucous resection of the septum. ${ }^{25}$

All three studies showed a significant short-term reduction in nasal airway resistance following septal 
TABLE I

PAPERS INITIALLY CONSIDERED BUT REJECTED ON FINAL READING

\begin{tabular}{|c|c|c|c|}
\hline Author(s) & Year & Title & Reason for rejection \\
\hline Barr $^{15}$ & 1989 & $\begin{array}{l}\text { The effect of submucous resection of the } \\
\text { septum on mucociliary transport and nasal } \\
\text { airway }\end{array}$ & No data for analysis provided \\
\hline Broms et al. ${ }^{16}$ & 1982 & $\begin{array}{l}\text { Rhinomanometry. IV. A pre- and } \\
\text { post-operative evaluation in functional } \\
\text { septoplasty }\end{array}$ & No control group \\
\hline Grymer et al. ${ }^{17}$ & 1989 & $\begin{array}{l}\text { Acoustic rhinometry: evaluation of the nasal } \\
\text { cavity with septal deviations, before and } \\
\text { after septoplasty }\end{array}$ & Minimal cross-sectional area data \\
\hline Holmstrom \& Kumlien ${ }^{18}$ & 1988 & $\begin{array}{l}\text { A clinical follow-up of septal surgery with } \\
\text { special attention to the value of } \\
\text { preoperative rhinomanometric } \\
\text { examination in the decision concerning } \\
\text { operation }\end{array}$ & No SDs given \\
\hline Jalowayski et al. ${ }^{19}$ & 1983 & $\begin{array}{l}\text { Surgery for nasal obstruction - evaluation by } \\
\text { rhinomanometry }\end{array}$ & Only pre-operative rhinomanometry data \\
\hline Larsen \& Oxhoj ${ }^{20}$ & 1988 & $\begin{array}{l}\text { Spirometric forced volume measurements in } \\
\text { the assessment of nasal patency after } \\
\text { septoplasty. }\end{array}$ & Nasal patency index measured \\
\hline Pirila \& Tikanto ${ }^{21}$ & 2001 & $\begin{array}{l}\text { Unilateral and bilateral effects of nasal } \\
\text { septum surgery demonstrated with acoustic } \\
\text { rhinometry, rhinomanometry, and } \\
\text { subjective assessment }\end{array}$ & Median data reported \\
\hline Nicklasson \& Sunden ${ }^{22}$ & 1982 & Rhinomanometry and septoplasty & No statistical analysis data \\
\hline Risavi et al. ${ }^{23}$ & 1988 & $\begin{array}{l}\text { Rhinomanometrical findings after septoplasty } \\
\text { in children }\end{array}$ & Medians, no SDs given \\
\hline Sipila \& Suonpaa ${ }^{7}$ & 1997 & $\begin{array}{l}\text { A prospective study using rhinomanometry } \\
\text { and patient clinical satisfaction to } \\
\text { determine if objective measurements of } \\
\text { nasal airway resistance can improve the } \\
\text { quality of septoplasty }\end{array}$ & No post-operative objective data \\
\hline
\end{tabular}

$\mathrm{SD}=$ standard deviation

surgery. A meta-analysis of the pooled data from the three studies, using the Mantel-Haenszel method, suggested that septal surgery does objectively improve nasal airflow, with an overall statistically significant effect at the 5 per cent level $(p=0.018)$. This is demonstrated graphically in a forest plot (Figure 1).

\section{Discussion}

Operations on the nasal septum are frequently performed with the intention of improving the nasal airway. For this reason, they form much of the routine workload in most otolaryngology departments. However, there is no agreed system for classifying septal deformities ${ }^{27}$ and the prevalence of septal deformity remains in doubt - although it has been estimated as varying between 1 and 80 per cent. ${ }^{28}$

As a result of this, there can be little agreement as to the diagnostic criteria that should be employed when considering a patient for surgery. However, even if there were more widely accepted objective criteria, there is frequently a poor correlation between the degree of septal deviation and the patient's complaints, and there is also little doubt that technical success does not correlate with relief of the patient's symptoms. ${ }^{21}$ Legitimate concern has therefore been raised as to whether this operation has any real value. ${ }^{3}$

Serendipity would suggest that such an extreme view is invalid. However, equally, it seems legitimate to ask whether the available literature on objective measurement before and after such surgery has shown any consistent trend to validate the procedure. Our study showed that, despite a huge available database of research on septal surgery and on the use of various methods to assess the airway, there was a paucity of reliable information in the available literature which gave any objective evidence of the value of this form of surgery. Even when there was apparently reasonable material, the methodology

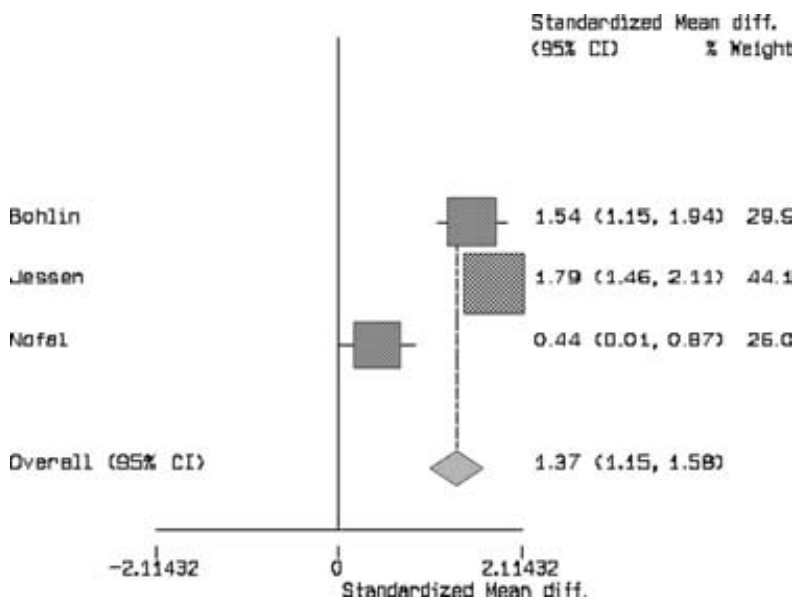

FIG. 1

Meta-analysis of data from the three relevant papers. Diff $=$ difference 
employed in the research was very often flawed and open to criticism. As a result of this, we found that most studies could not be retrospectively analysed and had to be rejected - usually because of a lack of properly reported data or because of failure to recognize the agreed criteria for measuring and reporting the results of investigation. In particular, the absence of information regarding patient posture, use of a rest period prior to measurement and patient drug history was common. In addition, few studies emphasized the need to demonstrate repeatability of their results.

In the light of this, the majority of studies were not suitable for meta-analysis. However, we did undertake such an analysis of the three papers that we felt demonstrated reasonable adherence to our agreed measurement protocols. The resultant calculation does demonstrate an overall significant improvement following surgery. Given the size of the original pool of articles, the limited number of trials eligible for final analysis is startling; such inadequate literature clearly cannot sustain any definitive, objective argument in favour of surgery.

- Surgery to the nasal septum is widely performed and the majority of surgeons would claim that it is effective in relieving nasal obstruction

- Doubts have been expressed as to the validity of septal surgery for symptoms of obstruction, and there is uncertainty as to the evidence base for such operations

- The present study examined the literature to systematically review the quality of objective information available concerning pre- and post-operative nasal airway performance

- The study agrees with previous analyses and concludes that there is a paucity of prospective and objective information to sustain the case for septal surgery. However, the available evidence suggests that these interventions confer objective benefit to the patient, at least in the short term

- Further properly conducted studies are needed. These would potentially both improve the process of informed consent and justify the continuance of this surgery to purchasers of healthcare

Operations on the nasal septum, as with other forms of surgery, are not without risk, and all surgeons would agree that both septoplasty and submucous resection are associated with potential morbidity from adhesions, bleeding and septal perforation. In addition, long-term cosmetic change, with columella retraction and saddling of the dorsum, may follow apparently successful surgery. Clearly, more standardized, long-term studies are needed to provide better data, and, if these are to be of value, they must adhere to agreed guidelines on patient documentation and standardization of the technique employed. This would then provide evidence to predict those who might properly benefit from such surgery as well as to validate an operation which is commonly perceived to help the vast majority of patients. Such studies would also help to facilitate the provision of proper informed consent to patients, as well as to justify the continuance of this form of surgery in a political environment which will, in the future, undoubtedly seek to validate and rationalize all surgical intervention.

\section{References}

1 Cumberworth VL, Narula AA, Bradley PJ. Prospective study of two management strategies for epistaxis. $J R$ Coll Surg Edinb 1991;36:259-60

2 Baker DC, Strauss RB. The physiologic treatment of nasal obstruction. Clin Plast Surg 1977;4:121-30

3 Roblin DG, Eccles R. What, if any, is the value of septal surgery? Clin Otolaryngol Allied Sci 2002;27:77-80

4 Siegel NS, Gliklich RE, Taghizadeh F, Chang Y. Outcomes of septoplasty. Otolaryngol Head Neck Surg 2000;122: 228-32

5 Stewart MG, Smith TL, Weaver EM, Witsell DL, Yueh B, Hannley MT et al. Outcomes after nasal septoplasty: results from the Nasal Obstruction Septoplasty Effectiveness (NOSE) study. Otolaryngol Head Neck Surg 2004;130: 283-90

6 Bohlin L, Dahlqvist A. Nasal airway resistance and complications following functional septoplasty: a ten-year follow-up study. Rhinology 1994;32:195-7

7 Sipila J, Suonpaa J. A prospective study using rhinomanometry and patient clinical satisfaction to determine if objective measurements of nasal airway resistance can improve the quality of septoplasty. Eur Arch Otorhinolaryngol 1997;254:387-90

8 Abu-Bakra M, Jones NS. Prevalence of nasal mucosal contact points in patients with facial pain compared with patients without facial pain. J Laryngol Otol 2001;115: $629-32$

9 Carney AS, Bateman ND, Jones NS. Reliable and reproducible anterior active rhinomanometry for the assessment of unilateral nasal resistance. Clin Otolaryngol Allied Sci 2000;25:499-503

10 Clarke JD, Hopkins ML, Eccles R. Evidence for correlation of objective and subjective measures of nasal airflow in patients with common cold. Clin Otolaryngol 2005:30:35-8

11 Clement PA. Committee report on standardisation of rhinomanometry. Rhinology 1984;22:151-5

12 Harar RP, Kalan A, Kenyon GS. Improving the reproducibility of acoustic rhinometry in the assessment of nasa function. ORL J Otorhinolaryngol Relat Spec 2002;64: $22-5$

13 Harar RP, Kalan A, Kenyon GS. Assessing the reproducibility of nasal spirometry parameters in the measurement of nasal patency. Rhinology 2001;39:211-14

14 Hilberg O. Objective measurement of nasal airway dimensions using acoustic rhinometry: methodological and clinical aspects. Allergy 2002;57S.70:5-39

15 Barr GS. The effect of submucous resection of the nasal septum on mucociliary transport and nasal airway. Clin Otolaryngol Allied Sci 1989;14:127-30

16 Broms P, Jonson B, Malm L. Rhinomanometry. IV. A preand postoperative evaluation in functional septoplasty. Acta Otolaryngol 1982;94:523-9

17 Grymer LF, Hilberg O, Elbrond O, Pedersen OF. Acoustic rhinometry: evaluation of the nasal cavity with septal deviations, before and after septoplasty. Laryngoscope 1989;99: $1180-7$

18 Holmstrom M, Kumlien J. A clinical follow-up of septal surgery with special attention to the value of preoperative rhinomanometric examination in the decision concerning operation. Clin Otolaryngol Allied Sci 1988;13:115-20 
19 Jalowayski AA, Yuh YS, Koziol JA, Davidson TM. Surgery for nasal obstruction - evaluation by rhinomanometry. Laryngoscope 1983;93:341-5

20 Larsen K, Oxhoj H. Spirometric forced volume measurements in the assessment of nasal patency after septoplasty. A prospective clinical study. Rhinology 1988;26:203-8

21 Pirila T, Tikanto J. Unilateral and bilateral effects of nasal septum surgery demonstrated with acoustic rhinometry, rhinomanometry, and subjective assessment. Am J Rhinol 2001;15:127-33

22 Nicklasson B, Sunden L. Rhinomanometry and septoplasty. J Laryngol Otol 1982;96:991-5

23 Risavi R, Pisl Z, Sprem N, Klapan I. Rhinomanometrical findings after septoplasty in children. Int J Pediatr Otorhinolaryngol 1988;16:149-55

24 Jessen M, Ivarsson A, Malm L. Nasal airway resistance and symptoms after functional septoplasty: comparison of findings at 9 months and 9 years. Clin Otolaryngol Allied Sci 1989;14:231-4

25 Nofal F, Thomas M. Rhinomanometry evaluation of the effects of pre- and postoperative SMR on exercise. J Laryngol Otol 1990;104:126-8
26 Broms P, Jonson B, Lamm CJ. Rhinomanometry. A system for numerical description of the nasal airway resistance. Acta Otolaryngol 1982;94:157-68

27 Guyuron B, Uzzo CD, Scull H. A practical classification of septonasal deviation and an effective guide to septal surgery. Plast Reconstr Surg 1999;104:2202-9

28 Jessen M, Janzon L. Prevalence of non-allergic nasal complaints in an urban and a rural population in Sweden. Allergy 1989;44:582-7

Address for correspondence:

Mr Arvind Singh,

22 Stonehall Avenue,

Redbridge IG1 3SH, UK.

E-mail: singha@doctors.org.uk

Mr A Singh takes responsibility for the integrity of the content of the paper.

Competing interests: None declared 